\title{
Motivation for Achievement and Attitudes toward Mathematics Instruction in a Required Calculus Course at the Norwegian University of Science and Technology
}

Donna Sundre

James Madison University, sundredl@jmu.edu

Carol Barry

The College Board, Newtown, PA, cabarry@collegeboard.org

Vidar Gynnild

Norwegian University of Science and Technology, Vidar.Gynnild@plu.ntnu.no

Erin Tangen Ostgard

Norwegian University of Science and Technology, eirintan@stud.ntnu.no

Follow this and additional works at: https://digitalcommons.usf.edu/numeracy

Part of the Mathematics Commons, and the Science and Mathematics Education Commons

\section{Recommended Citation}

Sundre, Donna, Carol Barry, Vidar Gynnild, and Erin T. Ostgard. "Motivation for Achievement and Attitudes toward Mathematics Instruction in a Required Calculus Course at the Norwegian University of Science and Technology." Numeracy 5, Iss. 1 (2012): Article 4. DOI: http://dx.doi.org/10.5038/1936-4660.5.1.4 


\title{
Motivation for Achievement and Attitudes toward Mathematics Instruction in a Required Calculus Course at the Norwegian University of Science and Technology
}

\author{
Abstract \\ This study from the Norwegian University of Science and Technology (NTNU) examines students' learning \\ goals and attitudes toward mathematics in a first-year calculus course in undergraduate engineering \\ education. Achievement motivation research using the Achievement Goal Questionnaire (AGQ) is \\ advanced from current literature with two additions: (1) a course specific context using introductory \\ college calculus students, and (2) participation of Norwegian students. \\ Pre- and posttest measures of attitudes indicate that students do change learning goals over time, \\ unfortunately opposite to the instructors' aspirations. A significant increase in "Mastery Avoidance" and \\ "Work Avoidance" was accompanied with a drop in "Mastery Approach" and "Performance Approach". \\ Variables such as value, motivation and enjoyment decreased along with a significant drop in self- \\ confidence.
}

\section{Keywords}

attitudes, achievement motivation, calculus

\section{Creative Commons License}

\section{(i) (9)}

This work is licensed under a Creative Commons Attribution-Noncommercial 4.0 License

\section{Cover Page Footnote}

Donna L. Sundre is a Professor of Graduate Psychology and Executive Director of the Center for Assessment and Research Studies at James Madison University. Her research interests include assessment practice, instrument design, examinee motivation, and student learning motivation goals.

Carol Barry is an Assistant Research Scientist at College Board in Newton, PA. Her research interests include test development, validity, motivational topics, and applications of structural equation modeling, growth modeling and mixture modeling.

Vidar Gynnild is Professor at the Norwegian University of Science and Technology (NTNU) in Trondheim, Norway. He is a faculty member of the Educational Development Service Office for the University.

Erin Tangen Ostgard is a graduate student at the Norwegian University of Science and Technology (NTNU) in statistics. 


\section{Introduction}

As we seek internationally to increase the numbers and competencies of students entering and succeeding in science, technology, engineering and mathematics (STEM) fields, it is important to explore the characteristics of those who succeed and those who do not. Many universities have been concerned with observed high failure rates in first-year required mathematics courses (see Symonds et al. 2010 for a recent UK example). We need to know more about how to build success as it relates to quantitative competencies and foundational skills both for STEM and for functioning in our quantitative world. Our focus in this paper is a required calculus course and how students changed. We expect our findings on attitudes and achievement motivation to apply more generally and to be of particular interest for the broad field of quantitative literacy.

Previous research has shown that patterns of achievement in mathematics and physics in secondary education reoccur in a first-year, mandatory calculus course in engineering education at the Norwegian University of Science and Technology (NTNU) (Gynnild et al. 2005). That study revealed a set of features that distinguish academically successful students from their less-successful peers. The higher the final grade in calculus, the fairer that students thought the assessment, and the higher the final grade, the more that students assumed the grade accurately reflected their competence. Conversely, students earning grades at the opposite end of the scale put less effort into their studies compared with high-performers, and were consistently having a hard time keeping up with the progression of the course. Academically less-successful students were also repeatedly struggling and did not care much about poor grades as long as they earned a pass. Merely passing the course with a minimum grade became the goal.

These findings may render the impression that the degree of success in calculus is more or less pre-determined on entry to university - that there is little space for interventions on the part of professors to constructively impact students' attitudes and behaviors. This is obviously not the whole truth, for attitudes and beliefs have been shown to change quite dramatically over a semester, and such changes can play major roles in subsequent academic and professional success (Marzano 2001).

In our current calculus study, a noticeable number of students (37) with top grades from secondary education failed their final calculus exam. In Norway, grades follow the European Credit Transfer System (ECTS), and range from grades of ' $A$ ' through ' $F$ ' (failing). A grade of ' $E$ ' is also possible and, unlike the American grade of ' $\mathrm{D}$ ', represents the lowest possible passing grade. Furthermore, while $30 \%$ of the students who either failed or received an "E" attended a voluntary preparatory calculus course, less than $10 \%$ of those who were assigned an "A" did so. Thus, many of these students who later struggled 
recognized a need for additional preparation and took advantage of opportunities. Unfortunately, these preparatory activities were not sufficient to assure success. It appears that additional attitudinal and behavioral changes took place during the semester. Attendance rates at the optional midterm exam exhibit a very different picture for these same students; those who received the best grades were far more likely to take the optional midterm when compared with those who later failed the final exam. Troubled students who opted for pre-semester voluntary opportunities were now shunning opportunities for feedback at mid-semester. Something must have happened along the way, but so far we have very little precise information about this.

Our data indicate that students change their attitudes and goals during the course of the semester, with some changing more than others. Some would argue that such affective development is as important as the promotion of skills and knowledge (e.g., Aloi et al. 2003). Attitudes can determine the extent to which learning occurs and how learning occurs (Marzano 2001); further, attitudes may impact students' abilities to function generally (Anderson et al. 2007). The impact of the affective domain in calculus is undisputed; however, to the authors' knowledge there is little emphasis on including affective objectives in calculus syllabi. This has been attributed to difficulties associated with course design issues, and with providing evidence to prove attitude changes (Kobella 1989).

\section{Educational Setting and Attitudes}

The term "attitude" is sometimes mentioned in course design descriptions along with learning objectives associated with "knowledge" and "skills." Stakeholders would agree that promoting attitudes is vital in education; however, the word is used in a variety of ways leading to considerable confusion (Kobella 1989). The affective domain in science education has been concerned primarily with attitudes related to science. Promoting positive attitudes in disciplines has been a legitimate goal for educators, encompassing a range of behaviors, e.g. prefer, accept, appreciate and commit (Kobella 1989). The most commonly explored attitudes have related to measuring change in students' feelings towards a specific course. Attitudes are not hereditary in a literal sense; attitudes can be learned and therefore taught. As Kobella (1989) rightly comments, the term "attitude" is often confused with other terms such as value, belief, interest and opinion. Some clarifications of the meaning of these terms are outlined in the following:

Values are rules that direct moral or ethical decisions that are considered with right or wrong. They are broader in scope than attitudes, and, unlike attitudes that range from positive to negative, values seem to be always positive in nature. ... Beliefs are the cognitive basis for attitudes. They provide information for attitudes by linking objects and attributes. A person has many more beliefs than attitudes and far fewer values than 
either attitudes or beliefs. ... Usually manifested in the form of verbal expression, opinions are more cognitive than attitudes (Kobella 1989).

Attitude changes are often highly sought after in education, and considerable effort has been devoted to explore ways in which such changes may occur. Social psychologists have identified seven major approaches to attitude change, subsuming a number of related theoretical models (Petty and Cacioppo 1986). These researchers contend that persuasion plays a key role; in this context, persuasion is defined as "any change in attitudes that results from exposure to communication" (Petty and Cacioppo 1986, p. 5). Contrary to this rather individualistic notion of change, frame factor theory emphasizes the impact of shaping forces in the learning environment (Dahllöf 1989). For example (Berg 2005), how could a calculus course be designed so as to encourage and strengthen positive sentiments and promote excitement and optimism for an increasing number of students throughout the semester?

There is an abundance of evidence that shaping forces in the educational setting, such as content, learning activities, time and modes of assessment, exert a profound impact on students' approaches to their task (Entwistle and Ramsden 2003). These relationships have not proven to be entirely straightforward, thus preventing any quick fix to urgent issues of learning. Students respond differently to the same educational environment, and changes may affect students to the detriment of intended outcome. A study of chemistry education asserts that "essentially the same factors in the educational setting had affected students with negative and positive attitude shifts. ... Students with positive attitude changes exhibited fewer negative views of educational factors, while students with negative attitude changes showed an opposite pattern" (Berg 2005, p. 1).

The current study represents the first attempt to explore the level of consistency in goals and attitudes of students enrolled in a first-year calculus course at NTNU. Our study takes a new and fresh approach compared with established quality assurance measures at NTNU. Specifically, the focus of this study is on students' intentionality (goals) and attitudes. Unlike current student evaluation of teaching forms, this study applies validated research instruments that have proven reliable and effective in an American educational context.

\section{Purpose of Study}

Our study has two sets of goals. First, we wish to explore whether students change (a) their goals in calculus over time and/or (b) their attitudes towards the particular course. Second, we wish to explore the utility and generalizability of the modified Achievement Goal Questionnaire to a required college calculus course context in Norway. 
The Achievement Goal Questionnaire (AGQ) (Elliot and McGregor 2001) has demonstrated excellent utility in many studies involving college students. Finney et al. (2004) modified the AGQ to address generic semester learning goals rather than course specific learning goals. Their research confirmed the fourfactor, $2 \times 2$ structure of the AGQ. This factor structure includes four independent measures: (1) Mastery Approach (MAP); (2) Mastery Avoidance (MAV); (3) Performance Approach (PAP); and (4) Performance Avoidance (PAV). The AGQ has also been expanded to include a fifth goal orientation, Work Avoidance (WAV), which has been alluded to in the literature (Pieper 2004). Harackiewicz and her colleagues (Harackiewichs et al. 2000; Harackiewichs et al. 1997) introduced items to assess work-avoidance as a potential learning goal. Together, these five goal orientations have provided illuminating information about student learning goals for research concerning general collegiate learning goals as well as learning goals pertaining to general education (Sundre and Miller 2006) and the major (Cid et al. 2007). These studies converge nicely with the finding that assessment results can be used as a strategy to improve both student attitudes and learning.

The current study extends this promise to a science and technology institution of higher education in Norway. As part of the same study the Attitudes Toward Math Instruction (ATMI) instrument was administered. A pre- and post-test design was used in a required introductory calculus course. Thus, a very powerful design was employed in an entirely new learning context.

\section{Methods}

\section{Participants and Procedures}

The subjects for the study were all students enrolled in a first-year introductory calculus course at the NTNU in fall of 2007. Introductory calculus (TMA4100) is a required course for all new students enrolled in engineering programs at NTNU. Participants in our study consisted of 1,580 Norwegian students who were administered the modified AGQ and the ATMI during the first week of classes. The same instruments were again administered to all students during the last class week. All participants completed the questionnaires during class time.

Students' attitudes toward learning were measured using the Achievement Goal Questionnaire (AGQ) (Elliot and McGregor 2001). This 16-item instrument produces five scores: (1) Mastery Approach (MAP); (2) Mastery Avoidance (MAV); Performance Approach (PAP); 4) Performance Avoidance (PAV); and 5) Work Avoidance. The items were translated into Norwegian and revised to address student learning goals for the course. Students were asked to respond to a series of statements using a scale from 1 (Not at all true of me) to 7 (Completely true of me). Items were summed to create five subscale scores, with higher scores 
indicating higher levels of that achievement goal. Research has found support for the five-factor structure of the ATL (e.g., Pieper 2004).

Students' attitudes toward math were measured using the Attitudes Toward Mathematics Instrument (ATMI) (Tapia 1996; Tapia and Marsh 2002). The ATMI consists of 40 items written to represent four subscales: self-confidence (15 items), value of mathematics (10 items), enjoyment of mathematics (10 items), and motivation to learn mathematics (5 items). Students were asked to respond to a series of statements using a scale from 1 (Strongly Disagree) to 5 (Strongly Agree). Negatively worded items were reverse scored and items were summed to create four subscale scores, with higher scores indicating higher levels of attitudes toward math.

\section{Results}

\section{Question I: Do Learning Goals Change Over Time}

To determine whether or not learning goals change over time, students were administered the AGQ twice during the semester. The first time point was in August, and the second time point was in November. Of the 1,580 students who were given the measure at time point one, 1,497 provided complete data for the AGQ. Of the 883 students who were given the measure at time point two, 831 provided complete data for the AGQ. However, in order to compare scores over time, only students who provided complete data for both time points were included. Thus, the effective sample size for the current analyses was $N=791$. Descriptive statistics and estimates of internal consistency reliability for each of the five AGQ subscales are in Table 1. These results indicate that the AGQ scales produce scores with sufficient reliability for research purposes.

Table 1.

Descriptive Statistics and Reliabilities for AGQ Subscales

\begin{tabular}{cccccccccc}
\hline & & \multicolumn{3}{c}{ Time 1} & & \multicolumn{3}{c}{ Time 2 } \\
\cline { 3 - 5 } \cline { 8 - 9 } Subscale & $k$ & Mean & SD & $\alpha$ & & Mean & SD & $\alpha$ \\
\hline MAP & 3 & 17.57 & 2.44 & 0.68 & & 15.89 & 3.03 & 0.75 \\
MAV & 3 & 12.31 & 3.90 & 0.79 & & 13.73 & 4.15 & 0.83 \\
PAP & 3 & 12.94 & 3.99 & 0.82 & & 11.28 & 4.31 & 0.87 \\
PAV & 3 & 10.06 & 3.64 & 0.61 & & 10.20 & 3.55 & 0.63 \\
WAV & 4 & 9.26 & 3.55 & 0.64 & & 10.84 & 3.81 & 0.65 \\
\hline
\end{tabular}

$* k$ indicates the number of items that make up the subscale. 
When examining the effective sample size to the total sample size, one might ask why there was such a large drop in the sample size from time 1 to time 2 . Unlike many colleges and individual courses in the United States, students are not required to attend classes in Norway. Thus, most first-year students typically attend classes to determine course structure and expectations. It is not uncommon for Norwegian students to spend considerable time studying independently or in groups, particularly just before final examinations. One might still query whether the drop in participation might impact the outcome of the study. That is, of the 1497 students who provided complete data at time 1, if those who also completed the measure at time 2 differed systematically from those who did not, it might limit the ability to generalize these results. To assess whether this was the case, initial AGQ scores for those who completed the instruments at time 2 (i.e., completers, $N=840$ ) were compared to the initial AGQ scores for those who did not (i.e., non-completers, $N=657$ ) using a between-subjects $t$-test for each AGO subscale separately. To control the Type-I error rate, alpha was set at $\alpha=.05 / 5=$ .01. Descriptive statistics and results are presented in Table 2. Additionally, for each test, Cohen's $d$ is reported as a measure of practical significance. Cohen (1988) provides benchmarks for this effect size: $d=.20$ indicates a small effect; $d$ $=.50$ indicates a medium effect; and $d=.80$ indicates a large effect.

These two groups of students (completers vs. non-completers) significantly differed in MAP and WAV, with those who completed both time points being higher in MAP and lower in WAV than those who did not. It should be noted, however, that the effect sizes for these differences are fairly small according to Cohen's (1988) standards. Additionally, in terms of raw scores, these differences did not exceed one point. Thus, although the results were found to be statistically significant, they do not differ from a practical standpoint.

Table 2.

Descriptive Statistics and $t$-test Results for AGQ Subscales

\begin{tabular}{|c|c|c|c|c|c|c|c|}
\hline Subscale & $k$ & Completers & $\begin{array}{c}\text { Mean (SD) } \\
\text { Non- } \\
\text { completers }\end{array}$ & Difference & $t$ & $p$ & $d$ \\
\hline MAP & 3 & $17.57(2.45)$ & $17.15(2.75)$ & 0.43 & 3.060 & 0.002 & 0.16 \\
\hline MAV & 3 & $12.31(3.88)$ & $12.42(3.99)$ & -0.05 & -0.567 & 0.571 & -0.03 \\
\hline PAP & 3 & $13.00(3.97)$ & $12.58(4.16)$ & 0.42 & 2.020 & 0.044 & 0.11 \\
\hline PAV & 3 & $10.07(3.62)$ & $10.12(3.81)$ & -0.12 & -0.263 & 0.793 & -0.01 \\
\hline WAV & 4 & $9.26(3.57)$ & $10.14(3.98)$ & -0.88 & -4.437 & $<.001$ & -0.23 \\
\hline
\end{tabular}

$* k$ indicates the number of items that make up the subscale. 
Given that these groups did not appear to differ from one another from a practical standpoint, we continued with the planned analyses. For each subscale of the AGQ, a dependent-samples $t$-test was conducted to determine whether change over time was statistically significant. Again, to control the Type-I error rate, alpha was set at $\alpha=.05 / 5=.01$. Additionally, for each test, Cohen's $d$ is reported as a measure of practical significance. Results are in Table 3. As shown in the table, MAP scores and PAP scores significantly decreased from time 1 to time 2, with effect sizes of -0.64 and -0.48 , respectively; these effect sizes are medium to large by Cohen's (1988) guidelines. Alternatively, MAV and WAV significantly increased over time, with effect sizes of 0.35 to 0.44 , respectively. These effect sizes are small to medium. PAV did not significantly change from time 1 to time 2 .

Table 3.

\begin{tabular}{lcccccc}
\multicolumn{6}{l}{ Dependent Samples $t$-test comparing Time 1 and Time 2 AGQ Subscale Scores } \\
\hline Subscale & $k$ & Mean Difference & SD of Difference & $t$ & $p$ & $d$ \\
\hline MAP & 3 & -1.68 & 2.63 & -18.003 & $<.001$ & -0.64 \\
MAV & 3 & 1.41 & 4.05 & 0.850 & $<.001$ & 0.35 \\
PAP & 3 & -1.69 & 3.50 & -13.606 & $<.001$ & -0.48 \\
PAV & 3 & 0.14 & 3.53 & 1.147 & 0.252 & 0.04 \\
WAV & 4 & 1.57 & 3.59 & 12.356 & $<.001$ & 0.44 \\
\hline
\end{tabular}

* $k$ indicates the number of items that make up the subscale.

The results of this analysis suggest that students do change in their learning goals over time. From the beginning to the end of the semester, there was a significant decrease in the two Approach goals (MAP and PAP), with both decreasing by about 1.7 points. There was also a significant increase in MAV and WAV, with both increasing by about 1.5 points. There was no change in PAV scores.

\section{Question II: Do Attitudes Toward Math Change Over Time}

Students were given the ATMI in August and November. Of the 1,580 students who were given the measure in August, 1,494 provided complete data for the ATMI. Of the 883 students who were given the measure in November, 813 provided complete data for the ATMI. In order to compare scores over time, only students who provided complete data for both time points were included. Thus, the effective sample size for the current analysis was $N=770$. Descriptive statistics and reliabilities for each of the four ATMI subscales are reported in 
Table 4. Review of the table indicates that the reliability estimates for each of the four subscales are more than adequate for research purposes.

Table 4.

Descriptive Statistics Reliabilities for ATMI Subscales

\begin{tabular}{|c|c|c|c|c|c|c|c|}
\hline \multirow[b]{2}{*}{ Subscale } & \multirow[b]{2}{*}{$k$} & \multicolumn{3}{|c|}{ Time 1} & \multicolumn{3}{|c|}{ Time 2} \\
\hline & & Mean & $\mathrm{SD}$ & $\alpha$ & Mean & SD & $\alpha$ \\
\hline Self-Confidence & 15 & 56.19 & 8.41 & 0.91 & 53.03 & 10.12 & 0.94 \\
\hline Value & 10 & 40.61 & 4.05 & 0.77 & 39.83 & 4.55 & 0.79 \\
\hline Motivation & 5 & 18.30 & 2.70 & 0.72 & 17.65 & 3.26 & 0.79 \\
\hline Enjoyment & 10 & 37.16 & 4.86 & 0.79 & 35.38 & 5.41 & 0.81 \\
\hline
\end{tabular}

*k indicates number of items that make up each subscale

Again, given the drop in sample size from time 1 to time 2, one might question whether this would impact the interpretation of the results. That is, of the 1494 students who provided complete data at time 1, if those who also completed the measure at time 2 differed systematically from those who did not, it might limit the ability to generalize these results. To assess whether this was the case, initial ATMI scores for those who completed the instruments at time 2 (i.e., completers, $N=837$ ) were compared to the initial ATMI scores for those who did not (i.e., non-completers, $N=657$ ) using a between subjects $t$-test for each ATMI subscale separately. To control the Type-I error rate, alpha was set at $\alpha=.05 / 5=$ .01 . Descriptive statistics and results are presented in Table 5. Again Cohen's $d$ is reported for each test as a measure of practical significance.

Table 5.

Descriptive statistics and t-test results comparing Time 1 ATMI scores for those who did and did not provide data at Time 2

\begin{tabular}{lcccccccc}
\hline & & \multicolumn{2}{c}{ Mean (SD) } & & & & \\
\cline { 3 - 4 } Subscale & $k$ & Completers & Non-completers & Difference & $t$ & $p$ & $d$ \\
\hline Self-Confidence & 15 & $56.05(8.55)$ & $53.67(10.46)$ & & 2.38 & 4.730 & $<0.001$ & 0.25 \\
Value & 10 & $40.64(4.15)$ & $40.20(4.53)$ & & 0.44 & 1.943 & 0.052 & 0.09 \\
Motivation & 5 & $18.29(2.77)$ & $17.57(3.32)$ & & 0.72 & 4.496 & $<0.001$ & 0.24 \\
Enjoyment & 10 & $37.18(4.97)$ & $35.61(6.10)$ & & 1.57 & 5.357 & $<0.001$ & 0.29 \\
\hline
\end{tabular}

$*_{k}$ indicates the number of items that make up the subscale

These two groups of students (completers vs. non-completers) significantly differed in Self-Confidence, Motivation, and Enjoyment with those who completed both time points being higher on all three sub-scores than those who 
did not. It should be noted, however, that the effect sizes for these differences are fairly small by Cohen's standards. That is, although the results were found to be statistically significant, they do not differ from a practical standpoint.

Given that those who did and did not provide complete data at time 2 did not appear to differ practically from one another, we continued on with our analyses. For each subscale, a dependent-samples $t$-test was conducted to determine whether change over time was statistically significant. To control the Type-I error rate, alpha was set at $\alpha=.05 / 5=.01$. Cohen's $d$ is also reported for each subscale as a measure of practical significance (see Table 6). As shown, all subscale scores significantly decreased from time point 1 to time point 2, with effect sizes ranging from -0.18 for Value to -0.47 for Enjoyment; these effect sizes are small to medium by Cohen's (1988) guidelines.

Table 6.

Dependent-Samples $t$-test comparing Time 1 and Time 2 ATMI Subscale Scores

\begin{tabular}{lcccccc}
\hline \multicolumn{1}{c}{ Subscale } & $k$ & Mean Difference & SD of Difference & $t$ & $p$ & $d$ \\
\hline Self-Confidence & 15 & -3.16 & 7.04 & -12.479 & $<.001$ & -0.45 \\
Value & 10 & -0.69 & 3.72 & -5.119 & $<.001$ & -0.18 \\
Motivation & 5 & -0.66 & 2.54 & -7.171 & $<.001$ & -0.26 \\
Enjoyment & 10 & -1.78 & 3.75 & -13.131 & $<.001$ & -0.47 \\
\hline
\end{tabular}

$*_{k}$ indicates the number of items that make up the subscale.

Our results suggest that students do change in their scores over time. From the beginning to the end of the semester, there was a significant decrease in all ATMI subscale scores. Specifically, Value and Motivation both decreased by less than 1 point, Enjoyment decreased by almost 2 points, and Self-Confidence decreased by a little over 3 points total. These results, however, should be accompanied by a strong word of caution. Although the psychometric properties of the ATMI have been studied to some extent (Tapia 1996; Tapia and Marsh 2002), further studies to determine the nature of its factor-structure and scoring are needed before trusting the inferences one makes about its scores. Our preliminary work suggests that although the scales, as introduced by Tapia and colleagues, appear to be reliable, the factor structure they proposed is not.

\section{Discussion}

Intentional learning objectives are essential in educational planning and course design; they enable communication between instructors and students in order to get a sense of where students are and how they can proceed to attain targeted learning. Explicit goals are useful in designing more effective learning activities 
and in the selection and construction of valid and reliable assessment instruments. From a program and department managerial perspective, clear learning objectives can facilitate better planning, program assessment, and use of assessment results for program improvement. The inclusion of course- and program-level goals associated with student attitudes and beliefs about learning should not be neglected.

In the required first-year calculus course studied, however, explicit learning objectives were missing. Students had no opportunity to self-check their levels of achievement against targeted outcomes, and by the time midterm examinations arrived, many, especially those least prepared, opted not to seek feedback on their performance. At this Norwegian institution, students were offered weekly calculus exercises, and towards the end of the semester, previous exams were available to help students form expectations of the types and difficulty of questions. We don't know much about how students approached their learning tasks, but our study has informed us about some rather disappointing changes in some of our students' learning goals and motivations to learn.

The achievement goal tradition, which forms the basis for our study of learning goals, relies on two types of goals known as "mastery goals" and "performance goals" (Elliot and McGregor 2001). As indicated by these two terms, mastery goals focus on the mastery of task, while performance goals reflect competence relative to others. According to Elliot and McGregor (2001), the two different types of goals lead to differential processes and outcomes. Our data suggest that our students' learning goals did change, unfortunately in the opposite direction of instructors' aspirations and expectations.

Over the course of the semester, we observed significant decreases both in "Mastery Approach" (MAP) and "Performance Approach" (PAP), whereas both "Mastery Avoidance" (MAV) and "Work Avoidance" (WAV) increased significantly. The decrease in "Mastery Approach" was the largest change observed. This result is crushing; it suggests that these students significantly decreased in their motivation to take advantage of a learning opportunity. The decrease in Performance Approach suggests that students were significantly less motivated by a desire to look good by earning higher grades. By the time the final examinations had arrived, earning high grades was no longer a realistic outcome for far too many of these students. For many of these students, the goal was now to achieve a grade of "D" or even "E", the lowest passing grades. The significant increases observed for "Mastery Avoidance" and "Work Avoidance" were also educationally unwelcome outcomes. The "Mastery Avoidance" increase indicates greater motivation related to the fear of not being able to learn and remember material. The "Work Avoidance" increase suggests a motivation to achieve a learning goal with a minimum of effort. Our data may be interpreted as a change from positive, desirable learning motivations to negative and educationally 
undesirable learning motivations. Unfortunately, these results are not all that uncommon in STEM related fields (Berg 2005, Symonds et al. 2010). It has become an international area of concern. In the United States, the National Science Foundation (NSF) is investing tens of millions of dollars to learn more about interventions that can impact attitudinal, affective, and learning outcomes (M. Boylan, November 21, 2011, e-mail message to author).

Our study results mirror those of Symonds et al. (2010), who found that, despite the establishment of a support system, their students exhibited a significant decrease in confidence in mathematics. They conducted qualitative follow up procedures that indicated that their less well prepared students were unable to adapt learning strategies that were appropriate for higher education. Our anecdotal evidence suggests that the transfer from Norwegian secondary to tertiary education is demanding. Classes are much bigger, progression is faster and with far less individual supervision from teachers compared with previous school years. Many of these Norwegian students entered the university to become engineers and may have underestimated the need for disciplined and selfregulated learning (Zimmerman and Schunk 2001). Previous research confirms that students do not always recognize their weaknesses (Osterlind et al. 1997), that they have an inflated sense of knowledge and skills in the actual field (Barnes et al. 2004), and are sometimes reluctant to invest time and energy into the study of mathematics (Grob and Kuehl 1997). It should be recalled that many of these same failing students volunteered for additional calculus preparatory work in advance of the semester. This learning strategy was not sufficient to prepare and sustain students through this required mathematics course.

The current study also provides useful information concerning collegiate attitudes about learning and math instruction. The results obtained support earlier findings concerning the importance of studying affective variables in college (Aloi et al. 2003; Pintrich et al. 1993). To date there is limited research on student affective development and its importance to learning (Anderson et al. 2007). The current study indicates changes in student attitudes about learning and mathematics over the course of a semester. More specifically, value, motivation and enjoyment decreased. In particular, our data show a dramatic drop in selfconfidence and enjoyment. Future research may shed light on why this occurs and what it means for students. This study brings evidence that could and most likely should form the basis for important discussions and follow-up studies at the university. This research has commenced. In a contrasting and reassuring study, Rheinlander and Wallace (2011) obtained increases in both enjoyment and confidence in mathematics use by collegiate students as a result of a course intentionally designed to enhance numeracy and transfer of knowledge. Their NSF-funded work provides important clues for instructional design, integration of course content to enhance relevancy, and student support throughout the course. 
The work of Braten and Olaussen (1998) and Gynnild et al. (2005) have made it clear that the American theoretical base for studying achievement motivation and student learning strategies appear to function well in Norway. The current study seems to suggest that both the AGQ and the ATMI measures provide reliable scores for research purposes. Both measures produced student scores that are similar to those observed in the United States.

\section{Concluding Remarks}

Explicit learning goals may be appreciated in their own right; however, more leverage of such goals are materialized in the selection of potent shaping forces in the educational environment, such as time and content, relevancy in assignments, teaching and learning activities, student mentoring and assessments. At NTNU and many other universities, exams in calculus deal exclusively with issues of mastery of content.. Hughes-Hallett (2003) made it clear through her work with students from her own and other universities, that the pedagogical techniques traditionally employed create persistent and negative attitudes about mathematics that impede quantitative literacy. Plug-and-chug drills and memorization establish stubborn attitudes by which compliance with rules trumps reasoning. Introducing instructional techniques that place mathematics in a broader context along with affective objectives would be one way to help direct attention to the relationship between goals, attitudes and learning. Such studies would most likely render useful data to further investigate the interrelatedness and significance of a range of variables in the learning context, such as how to foster desired attitudes.

Internationally, most studies have focused on ways in which courses affect attitudes related to the study material (Berg 2005; Kobella 1989), or approaches to learning (Eck 2002; Entwistle and Ramsden 2003). This study further illustrates the need for similar studies locally, which supports Scheaffer's (2008) call for much stronger quantitative literacy research that should be closely integrated with teaching. The application of valid and reliable surveys may be the first step to raise awareness through which action can be taken to bring about change. Without more careful attention to both learning of content and attitudes about learning and content, we cannot hope to positively impact student retention in collegiate pathways that lead to STEM-related fields. Further, our efforts to enhance the numeracy of our collegiate students will be impaired by not having the appropriate evidence to seek more effective solution strategies. 


\section{References}

Aloi, S. L., W. S. Gardiner, and A. L. Lusher. 2003. A framework for assessing general education outcomes within majors. The Journal of General Education 52(4): 237-252. http://dx.doi.org/10.1353/jge.2004.0009

Anderson, M. W., M. Teisl, G. Criner, S. Tisher, S. Smith, M. Hunter, et al. 2007. Attitude changes of undergraduate university students in general education courses. The Journal of General Education 56(2): 149-168.

Barnes, G. R., P. B. Cerrito, and I. Levi. 2004. An assessment of general education mathematics courses via examination of student expectations and performance. The Journal of General Education 53(1): 20-36. http://dx.doi.org/10.1353/jge.2004.0017

Berg, C. A. R. 2005. Factors related to observed attitude change toward learning chemistry among university students. Chemistry Education Research and Practice 6(1): 1-18. http://dx.doi.org/10.1039/b4rp90001d

Braten, I., and B. S. Olaussen. 1998. The relationship between motivational beliefs and learning strategy use among Norwegian college students. Contemporary Educational Psychology 25: 54-67.

Cid, J. A., D. L. Sundre, R. A. DePaolis, and V. A. Reed. 2007. Academic motivation: Achievement goal orientation differences between sophomore and senior undergraduates. Paper presented at the Association for Psychological Science (APA), 19th Annual Convention, May.

Cohen, J. 1988. Statistical power analysis for the behavioral sciences, 2 nd ed. Hillsdale, NJ: Lawrence Earlbaum Associates.

Dahllöf, U. 1989. En återblick på det tidiga ramfaktorteoretiske tänkandet odh några av dess senare utlöpare. In I laerande fellesskap. Helsingsskrift til Urban Dahllöf på 70-årsdagen, ed. R. Kvalsund, L. Bøe and K. Heggen, 11-45. Volda: Høgskulen i Volda/Møreforskning.

Eck, J. C. 2002. Assessing student outcomes im general education at Samford University. The Journal of General Education 51(4): 316-325. http://dx.doi.org/10.1353/jge.2003.0010

Elliot, A., and H. McGregor. 2001. A $2 \times 2$ achievement goal framework. Journal of Personality and Social Psychology 80(3): 501-519. http://dx.doi.org/ 10.1037/0022-3514.80.3.501

Entwistle, N., and P. Ramsden. 2003. Understanding student learning. London: Croom Helm.

Finney, S. J., S. L. Pieper, and K. E. Barron. 2004. Examining the psychometric properties of the Achievement Questionnaire in a general academic context. Educational and Psychological Measurement 64(2): 365-383.

Grob, L., and J. R. Kuehl. 1997. Coherence and assessment in a general education program. Liberal education 83: 34-39. 
Gynnild, V., J. Tyssedal, and L. Lorentzen. 2005. Approaches to study and the quality of learning. Some empirical evidence from engineering education. International Journal of Science and Mathematics Education 3(4): 587-607. http://dx.doi.org/10.1007/s10763-005-5178-4

Harackiewicz, J. M., K. Barron, J. Tauer, S. Carter, and A. Elliot. 2000. Shortterm and long-term consequences of achievement goals: Predicting interest and performance over time. Journal of Educational Psychology 92: 316-330. http://dx.doi.org/10.1037/0022-0663.92.2.316

Harackiewicz, J. M., K. E. Barron, S. Carter, A. Lehto, and A. Elliot. 1997. Predictors and consequences of achievment goals in the college classroom: Maintaining interest and making the grade. Journal of Personality and Social Psychology 73, 1284-1295. http://dx.doi.org/10.1037/0022-3514.73.6.1284

Hughes-Hallett, D. 2003. The role of mathematics courses in the development of quantitative literacy. In Quantitative literacy: Why numeracy matters for schools and colleges. ed. B. L. Madison and L. A. Steen, 91-98. Princeton, NJ: National Council on Education and the Disciplines.

Kobella, T. R. 1989. Changing and measuring attitudes in the science classroom. Retrieved 01.09.09, from National Association for Research in Science Teaching: http://www.narst.org/publications/research/attitude.cfm

Marzano, R. J. 2001. Designing a new taxonomy of education objectives. Thousand Oaks, CA: Corwin Press.

Osterlind, S. J., R. D. Robinson, and N. M. Nickens. 1997. Relationship between collegians' perceived knowledge and congeneric tested achievement in general education. Journal of College Student Development 38 255-265.

Petty, R. E., and J. T. Cacioppo. 1986. Communication and Persuasion. New York: Springer-Verlag.

Pieper, S. L. 2004. Refining and extending the $2 \times 2$ achievement goal framework: Another look at work-avoidance. (Doctoral dissertation, James Madison University, 2003). Dissertation Abstracts International 64: 4436.

Pintrich, P. R., R. W. Marx, and R. A. Boyle. 1993. Beyond cold conceptual change: The role of motivational beliefs and classroom contextual factors in the process of conceptual change. Review of Educational Research 63(2): 167-199. http://dx.doi.org/10.2307/1170472

Rheinlander, K., and D. and Wallace, D. 2011. Calculus, biology and medicine: A case study in quantitative literacy for science students. Numeracy, 4 (1):

Article 3. http://dx.doi.org/10.5038/1936-4660.4.1.3

Scheaffer, Richard L. 2008. Scientifically based research in quantitative literacy: Guidelines for building a knowledge base. Numeracy 1 (1): Article 3. http://dx.doi.org/10.5038/1936-4660.1.1.3

Sundre, D. L., and B. J. Miller, 2006. Advancing faculty engagement in direct measures of student learning: Quantiative and Scientific Reasoning. The 
Assessment Institute. Presented to faculty of Norwegian Institute of Science and Technology. Trondheim, Norway, October.

Symonds. R., D. Lawson, and C. Robinson 2010. An investigation of physics undergraduates' attitudes toward mathematics. Teaching Mathematics and its Applications 29: 140-154. http://dx.doi.org/10.1093/teamat/hrq009

Tapia, M. 1996. The attitudes towards mathematics instrument. Paper presented at the Mid-South Educational Research Association, November.

_., and G. E. Marsh. 2002. Confirmatory factor analysis of the Attitudes Toward Mathematics Inventory. Paper presented at the Mid-South Educational Research Assocication, November.

Zimmerman, B. J., and D. H. Schunk. 2001. Self-regulated learning and academic achievement: theoretical perspectives, 2nd ed.. Mahwah, NJ: Lawrence Erlbaum.

\section{Appendix}

\section{Achievement Goals Questionnaire (AGQ)}

The following statements concern your attitudes toward learning and performance in this class. Please indicate how true each statement is of you. If you think the statement is true of you, mark a 7. If a statement is not at all true of you, mark a 1. If the statement is more or less true of you, find the number between 7 and 1 that best describes you. There are no right or wrong answers. Just answer as accurately as possible.

\begin{tabular}{|cccccc|c|}
\hline 1 & 2 & 3 & 4 & 5 & 6 & 7 \\
Not at all true of me & & & & & & Very true of me \\
\hline
\end{tabular}

1. My goal in this course is to get better grades than most of the other students.

2. I just want to avoid doing poorly compared to other students in this course.

3. Completely mastering the material in this course is important to me.

4. I really don't want to work hard in this course.

5. I'm afraid that I may not understand the content of this course as thoroughly as I'd like.

6. It is important for me to do well compared to other students.

7. I want to learn as much as possible in this course.

8. The fear of performing poorly in this course is what motivates me. 
9. I want to do as little work as possible in this course.

10. The most important thing for me in this course is to understand the content as thoroughly as possible.

11. I worry that I may not learn all that I possibly could in this course.

12. I want to do better than other students in this course.

13. I want to get through this course by doing the least amount of work possible.

14. I am definitely concerned that I may not learn all that I can in this course.

15. My goal in this course is to avoid performing poorly compared to other students.

16. I look forward to working really hard in this course.

\section{AGQ Scoring Key}

PAP: Performance-Approach Items $(k=3): 1+6+12$

MAP: Mastery-Approach Items $(k=3): 3+7+10$

PAV: Performance-Avoidance Items $(k=3): 2+10+17$

MAV: Mastery-Avoidance Items $(k=6): 5+11+14$

WAV: Work Avoidance Items ( $k=4): 4+9+13+16$ (reverse-scored)

GOAL Item

PAP 1. My goal in this course is to get better grades than most of the other students.

PAV 2. I just want to avoid doing poorly compared to other students in this course.

MAP 3. Completely mastering the material in this course is important to me.

WAV 4. I really don't want to work hard in this course.

MAV 5. I'm afraid that I may not understand the content of this course as thoroughly as I'd like.

PAP 6. It is important for me to do well compared to other students.

MAP 7. I want to learn as much as possible in this course.

PAV 8. The fear of performing poorly in this course is what motivates me.

WAV 9. I want to do as little work as possible in this course.

MAP 10. The most important thing for me in this course is to understand the content as thoroughly as possible. 
MAV 11. I worry that I may not learn all that I possibly could in this course.

PAP 12. I want to do better than other students in this course.

WAV 13. I want to get through this course by doing the least amount of work possible.

MAV 14. I am definitely concerned that I may not learn all that I can in this course.

PAV 15. My goal in this course is to avoid performing poorly compared to other students.

WAV 16. I look forward to working really hard in this course. (REVERSE)

\section{ATMI Scoring Key}

Self-confidence Items ( $k=15): 1,3,5,6,8,9,12,15,16,19,21,22,27,31,32,38$

Value, importance of Mathematics Items ( $k=3): 2,4,7,11,13,14,18,20,36,37$

Motivation to learn math Items $(k=7): 10,25,26,28,29,17,34$

Enjoyment of Math Items ( $k=8): 23,24,30,33,35,39,40$

Reverse Scored Items ( $k=6): 3,9,15,17,21,27,31,34,38$

\section{Key to Table}

SE: Self-confidence/sense of security
VA: Value, importance of Mathematics
MO: Motivation to learn math
EN: Enjoyment of Math

EN: Enjoyment of Math

\begin{tabular}{|c|c|c|c|c|}
\hline $\begin{array}{l}\text { New } \\
\text { number }\end{array}$ & $\begin{array}{l}\text { Original } \\
\text { number* }\end{array}$ & Item Text & $\begin{array}{l}\text { Sub- } \\
\text { scale }\end{array}$ & $\mathbf{R} ?$ \\
\hline 1 & 17 & $\begin{array}{l}\text { I have a lot of self-confidence when it comes to } \\
\text { mathematics }\end{array}$ & $\mathrm{SE}$ & \\
\hline 2 & 8 & $\begin{array}{l}\text { I can think of many ways that I use math outside of } \\
\text { school }\end{array}$ & VA & \\
\hline 3 & 14 & $\begin{array}{l}\text { When I hear the word mathematics, I have a feeling of } \\
\text { dislike }\end{array}$ & SE & $\mathrm{R}$ \\
\hline 4 & 5 & Mathematics is important in everyday life & VA & \\
\hline 5 & 18 & $\begin{array}{l}\text { I am able to solve mathematics problems without too } \\
\text { much difficulty }\end{array}$ & SE & \\
\hline 6 & 20 & I am always confused in my mathematics class & SE & \\
\hline 7 & 33 & I am comfortable answering questions in math class & VA & \\
\hline 8 & 22 & I learn mathematics easily & SE & \\
\hline
\end{tabular}




\begin{tabular}{|c|c|c|c|c|}
\hline 9 & 11 & Studying mathematics makes me feel nervous & SE & $\mathrm{R}$ \\
\hline 10 & 36 & $\begin{array}{l}\text { I plan to take as much mathematics as I can during my } \\
\text { education }\end{array}$ & MO & \\
\hline 11 & 37 & $\begin{array}{l}\text { A strong math background could help me in my } \\
\text { professional life }\end{array}$ & VA & \\
\hline 12 & 32 & I believe I am good at solving math problems & SE & \\
\hline 13 & 1 & Mathematics is a very worthwhile and necessary subject & VA & \\
\hline 14 & 6 & $\begin{array}{l}\text { Mathematics is one of the most important subjects for } \\
\text { people to study }\end{array}$ & VA & \\
\hline 15 & 15 & $\begin{array}{l}\text { It makes me nervous to even think about having to do a } \\
\text { mathematics problem }\end{array}$ & SE & $\mathrm{R}$ \\
\hline 16 & 16 & Mathematics does not scare me at all & SE & \\
\hline 17 & 25 & I would like to avoid using mathematics in college & $\mathrm{MO}$ & $\mathrm{R}$ \\
\hline 18 & 7 & $\begin{array}{l}\text { High school math courses would be very helpful no } \\
\text { matter what I decide to study }\end{array}$ & VA & \\
\hline 19 & 9 & Mathematics is one of my most dreaded subjects & SE & $\mathrm{R}$ \\
\hline 20 & 2 & I want to develop my mathematical skills & VA & \\
\hline 21 & 10 & $\begin{array}{l}\text { My mind goes blank and I am unable to think clearly } \\
\text { when working with mathematics }\end{array}$ & SE & $\mathrm{R}$ \\
\hline 22 & 24 & I am confident that I could learn advanced mathematics & SE & \\
\hline 23 & 31 & $\begin{array}{l}\text { I would prefer to do an assignment in math than to write } \\
\text { an essay }\end{array}$ & EN & \\
\hline 24 & 34 & Mathematics is a very interesting subject & EN & \\
\hline 25 & 38 & The challenge of math appeals to me & MO & \\
\hline 26 & 39 & I think studying advanced mathematics is useful & MO & \\
\hline 27 & 12 & Mathematics makes me feel uncomfortable & SE & $\mathrm{R}$ \\
\hline 28 & 27 & $\begin{array}{l}\text { I am comfortable expressing my own ideas on how to } \\
\text { look for solutions to a difficult problem in math }\end{array}$ & MO & \\
\hline 29 & 28 & I really like mathematics & MO & \\
\hline 30 & 3 & $\begin{array}{l}\text { I get a great deal of satisfaction out of solving a } \\
\text { mathematics problem }\end{array}$ & EN & \\
\hline 31 & 13 & I am always under a terrible strain in a math class & SE & $\mathrm{R}$ \\
\hline 32 & 19 & I expect to do fairly well in any math class I take & SE & \\
\hline 33 & 26 & I like to solve new problems in mathematics & EN & \\
\hline 34 & 30 & Mathematics is dull and boring & MO & $\mathrm{R}$ \\
\hline 35 & 35 & $\begin{array}{l}\text { I am willing to take more than the required amount of } \\
\text { mathematics }\end{array}$ & EN & \\
\hline 36 & 40 & $\begin{array}{l}\text { I believe studying math helps me with problem solving in } \\
\text { other areas }\end{array}$ & VA & \\
\hline 37 & 4 & $\begin{array}{l}\text { Mathematics helps develop the mind and teaches a } \\
\text { person to think }\end{array}$ & VA & \\
\hline 38 & 21 & I feel a sense of insecurity when attempting mathematics & SE & $\mathrm{R}$ \\
\hline 39 & 23 & I have usually enjoyed studying mathematics in school & EN & \\
\hline 40 & 29 & I am happier in a math class than in any other class & EN & \\
\hline
\end{tabular}

*The item number from the scale as it was presented by Tapia (1996) and Tapia and Marsh (2002). The order of the items was randomized for the current administration and the item number from the instrument used in this study is in column "new number". 